\title{
The scent world of cats: where to place a urine scent mark to increase signal persistence?
}

\author{
Mohorović Maja ${ }^{1, *}$ and Krofel Miha ${ }^{2}$ \\ ${ }^{1}$ Potok 49, SI-8351 Straža, Slovenia \\ ${ }^{2}$ Department of Forestry, Biotechnical Faculty, University of Ljubljana, Večna pot 83, SI-1000 \\ Ljubljana, Slovenia
}

Submitted: April 27, 2020. Final revision received: September 4, 2020. Accepted: September 22, 2020

*) Corresponding author: maja.mohorovic@gmail.com

\begin{abstract}
Scent-marking is a predominant form of communication among felids, with urine spraying having a key role. Detectability and longevity of scent marks are recognized as crucial for efficiency of scentmarking, but there is limited research that has tested scent persistence with respect to various environmental factors. We used an experimental framework to measure human-perceived strength of felid urine smell and determine the effects of substrate, tilt and aspect of marked surfaces on persistence of the simulated scent marks. We used area under the curve (AUC), calculated for the scent strength of each scent-marked surface over time, as a proxy for urine scent preservation. Thereafter, we used ANOVA, followed by analysis of differences of interest between the marking sites, to assess the effect of environmental factors on human-perceived scent mark persistence. Odour persisted significantly better on rough surfaces, surfaces covered with moss and on surfaces with overhanging tilts, while there was no significant difference between the northerly- and southerly-oriented surfaces. The results are generally in accordance with the use and selection of marking sites previously reported for wild felids throughout the world, confirming that in their marking behaviour felids strive to prolong the persistence of scent marks. This knowledge will help researchers in interpretation of data on scent-marking and to evaluate the adaptive significance of this behaviour.
\end{abstract}

\section{Keywords}

cats; felids; olfactory communication; pheromone; scent-marking; territory, urine spraying 


\section{Introduction}

Scent-marking plays an important role in the communication system of many mammal species (Kimura, 2000; Mertl-millhollen, 2006; Nie et al., 2012; Haswell et al., 2018). While other communication strategies, such as visual and acoustic signals, are limited in space and time (Rosenthal \& Ryan, 2000), scent signals are long-lasting (Vogt et al., 2014) and can be effectively used also when visibility is poor (Gorman \& Trowbridge, 1989). This makes scent-marking particularly advantageous for solitary species, because it allows a signal to reach a receiver indirectly, when the signalling animal is absent (Gosling \& Roberts, 2001).

Mammals are known to use a variety of behaviours to communicate via scent with conspecifics and allospecifics: urination (Krofel et al., 2017; Haswell et al., 2018), defecation (Barja, 2009), glandular rubbing (Hirano et al., 2008), scratching and scraping (Gese \& Ruff, 1997; Allen et al., 2016a), and thrashing (Black-Décima, 2000). Such chemical scent-marking may serve various purposes, including advertisement of reproductive status and mate selection (Bailey, 1974; Allen et al., 2015), establishment and defence of a territory (Roper et al., 1993), prevention of agonistic and potentially fatal encounters (Smith et al., 1989; Mattisson et al., 2013), indication of dominance (Clapham et al., 2012), identification of individuals and their relatedness (Rostain et al., 2004), defence of food resources (Remonti et al., 2011) and information on individual health conditions (Zala et al., 2004).

Scent-marking is a predominant form of communication among most solitary felid species with urine spraying typically representing the primary method (Smith et al., 1989; Mellen, 1993; Feldman, 1994; Sunquist \& Sunquist, 2002; Vogt et al., 2014; Caragiulo et al., 2015; Allen et al., 2016a; Krofel et al., 2017). Because of its chemical composition, it is suggested that marks made with urine play a key role in reproductive behaviour and social organisation in wild felids (Vogt et al., 2016a). Regardless of the marking mode, the ability to transmit information into the future is the most important feature of scent signals in solitary felid species (Alberts, 1992; Kitchener, 2000; Vogt et al., 2014; Allen et al., 2017). Prolonged persistence of scent marks can decrease the need to frequently refresh the scent signals and thus increase the efficiency of scent-marking (Allen et al., 2017) and stronger intensity of a signal can attract conspecifics more effectively (Alberts, 1992).

Detectability and longevity of scent marks can be increased by releasing a greater amount of scent material (Alberts, 1992), such as urine. However, higher production and frequent refreshment of scent marks demand considerable energetic costs (Gosling \& Roberts, 2001). Thus, increasing signal efficiency only by a higher amount of secretions may not be evolutionary economical. Indeed, 
several studies suggested that animals exhibit various behavioural or physiological adaptations that help to increase signalling efficiency, such as using conspicuous scent-marking locations to increase detection probability (Gosling \& Roberts, 2001; Soler et al., 2009; Piñeiro \& Barja, 2012; Vogt et al., 2014), and prolonging duration of the message through either chemical composition (Alberts, 1992; Asa, 1993; Vogt et al., 2016a) or through selecting certain microsites for scent-marking that better retain the scent of the deposited mark (Allen et al., 2017).

Several authors hypothesized that certain substrate types, tilts or orientations of the surface selected for scent-marking increase the durability of felid scent marks (Ahlborn \& Jackson, 1988; Smith et al., 1989; Bothma \& le Richet, 1995; Jackson, 1996; Sharma et al., 2006; Piñeiro \& Barja, 2012; Ruiz-Olmo et al., 2013; Allen et al., 2017). However, to our knowledge these assumptions have never been systematically tested despite the need for such a study (e.g. Alberts, 1992; Sharma et al., 2006; Nie et al., 2012; Allen et al., 2017).

We used an experimental framework to measure longevity and strength (collectively referred to as persistence hereafter) of felid urine deposited on various substrate types, surface tilts and aspects, based on a human perception of smell. Existing scientific literature on urine scent-marking in felids indicates a preference for certain objects and their characteristics that are expected to better retain smell (see table 1 for a review). Thus, we compared human-perceived persistence of simulated felid urine marks on tree trunks with different bark roughness (coniferous vs. deciduous tree trunks), juvenile conifers, bare rocks and rocks covered with moss. We also compared between northwardand southward-facing surfaces of these objects, as well as among bare rocks with vertical, sloping and overhanging tilts. We predicted that smell of urine will persist for longer on coniferous tree trunks and rocks with moss. Rough surfaces are assumed to better retain scent than smooth surfaces due to larger number of potential binding sites, which slow down the evaporation of odorants from the surface (Conover, 2007), and are also expected to provide a more adhesive surface (Barja, 2009). Rough surfaces such as rough bark may also capture more urine in the crevices, which is expected to make urine marks more weather-resistant (Nie et al., 2012). Similarly, it was suggested that the presence of moss increases the surface area of the object and captures more urine, which could prolong the durability of a scent message (Allen et al., 2017). We further expected urine smell to fade faster on bare rocks compared to vegetation since plants are supposed to contain chemicals that slow down the release of volatiles (Barja, 2003; Ruiz-Olmo et al., 2013; Allen et al., 2017). We also expected the urine to persist better on northerly-oriented surfaces, which are (in the Northern Hemisphere) believed to enhance the longevity of scent marks by sheltering them from environmental factors (Ahlborn \& Jackson, 1988; Jackson, 1996), especially from sunlight and higher temperatures, which increases evaporation (Conover, 2007). Finally, we predicted that scent will be 
more persistent on overhanging and vertical tilt than on sloping rocks, because the scent is better sheltered from precipitation (Ahlborn \& Jackson, 1988; Allen et al., 2017).

Table 1: Review of the urine scent-marking site characteristics for felids reported in the scientific literature.

\begin{tabular}{|c|c|c|c|c|c|}
\hline Species & Area & Substrate type & Slope & Orientation & Source \\
\hline \multirow[t]{2}{*}{$\begin{array}{l}\text { Eurasian } \\
\text { Iynx (Lynx } \\
\text { lynx) }\end{array}$} & Slovenia & $\begin{array}{l}\text { - juvenile conifers (S, FU) } \\
\text { - rocks with moss (FU) } \\
\text { - rocks (A, FU) } \\
\text { - tree stumps/trunks (FU) } \\
\text { - other vegetation (A, OU) } \\
\text { - human and other objects } \\
\text { (OU) }\end{array}$ & $\begin{array}{l}\text { - sloping rocks } \\
\text { (A) } \\
\text { - vertical rocks } \\
\text { (FU) }\end{array}$ & $\begin{array}{l}\text { - southwest, east, } \\
\text { west (FU) }\end{array}$ & $\begin{array}{l}\text { Allen et al., } \\
2017\end{array}$ \\
\hline & Swiss Alps & $\begin{array}{l}\text { - rocks - vertical faces of } \\
\text { rocky structures (FU) } \\
\text { - young conifers up to } 1 \mathrm{~m} \\
\text { in height (FU) } \\
\text { - adult conifers (trunk or } \\
\text { low branches marked) and } \\
\text { stumps (FU) } \\
\text { - deciduous trees, } \\
\text { woodpiles, conifers up to } \\
2 \text { m in height, logs, roots, } \\
\text { shrubs, tufts of grass, } \\
\text { grounds and other } \\
\text { objects (OU) }\end{array}$ & & & $\begin{array}{l}\text { Vogt et al., } \\
2014 \\
2016 b\end{array}$ \\
\hline $\begin{array}{l}\text { European } \\
\text { wildcat } \\
\text { (Felis } \\
\text { silvestris) }\end{array}$ & $\begin{array}{l}\text { Catalonia, } \\
\text { Spain* }\end{array}$ & $\begin{array}{l}\text { - common juniper (S) } \\
\text { - strawberry trees (A) } \\
\text { - box wood (OU) } \\
\text { - other plant species, such } \\
\text { as barberry, rosemary etc. } \\
\text { (A) }\end{array}$ & & & $\begin{array}{l}\text { Ruiz-Olmo } \\
\text { et al., } \\
2013^{*}\end{array}$ \\
\hline $\begin{array}{l}\text { Cheetah } \\
\text { (Acynonix } \\
\text { jubatus) }\end{array}$ & Kenya & $\begin{array}{l}\text { - large trees and shrubs, dirt } \\
\text { mounds, concrete road } \\
\text { embankments (FU) }\end{array}$ & & & $\begin{array}{l}\text { Eaton, } \\
1970\end{array}$ \\
\hline \multirow{2}{*}{$\begin{array}{l}\text { Snow } \\
\text { leopard } \\
\text { (Panthera } \\
\text { uncia) }\end{array}$} & India & & $\begin{array}{l}\text { - overhanging } \\
\text { rocks } \\
\text { (S) }\end{array}$ & $\begin{array}{l}\text { - north \& west (S) } \\
\text { - south \& east (A) }\end{array}$ & $\begin{array}{l}\text { Sharma et } \\
\text { al., } 2006\end{array}$ \\
\hline & Nepal & $\begin{array}{l}\text { - boulders or rock } \\
\text { outcrops (FU) } \\
\text { - base of a cliff face (OU) }\end{array}$ & $\begin{array}{l}\text { - overhanging } \\
\text { rocks (FU) }\end{array}$ & - north (FU) & $\begin{array}{l}\text { Ahlborn \& } \\
\text { Jackson, } \\
1988 ; \\
\text { Jackson, } \\
1996\end{array}$ \\
\hline $\begin{array}{l}\text { Leopard } \\
\text { (Panthera } \\
\text { pardus) }\end{array}$ & $\begin{array}{l}\text { Kalahari, } \\
\text { South } \\
\text { Africa }\end{array}$ & $\begin{array}{l}\text { - tree trunks, shrubs and } \\
\text { grass, ground (OU) }\end{array}$ & & & $\begin{array}{l}\text { Bothma \& } \\
\text { le Richet, } \\
1995\end{array}$ \\
\hline $\begin{array}{l}\text { Tiger } \\
\text { (Panthera } \\
\text { tigris) }\end{array}$ & Nepal & - trees and shrubs (FU) & $\begin{array}{l}\text { overhanging } \\
\text { side of the trees } \\
\text { (FU) }\end{array}$ & & $\begin{array}{l}\text { Smith et } \\
\text { al., } 1989\end{array}$ \\
\hline
\end{tabular}

Abbreviations: A, avoidance in urine spraying; FU, frequently used for urine spraying; OU, occasionally used for urine spraying; $\mathrm{S}$, selection in urine spraying; ${ }^{*}$, study conducted in captivity. 
Selection and avoidance data represent use with respect to availability, while use data (frequently used, occasionally used) represent only the frequency observed for urine-spraying among microsites with different characteristics. The latter may be problematic, because frequent use may be merely a consequence of high availability of specific marking objects in a study area. Thus, we treated selection and avoidance data (bolded) as more reliable.

\section{Materials and methods}

\section{Study area characteristics and weather conditions}

We conducted the experiment in a typical habitat of wild felids (Eurasian lynx Lynx lynx and European wildcat Felis silvestris) in the Northern Dinaric Mountains in Slovenia $\left(45^{\circ} 45.5^{\prime} \mathrm{N}, 15^{\circ} 06.5^{\prime} \mathrm{E}\right.$, elevation $\sim 240 \mathrm{~m}$, fig. 1), where the limestone and dolomite geology results in a rugged karstic relief and abundant karstic structures, such as cliffs, dolines, caves and rock shelters. The predominant forest type is an association of European beech (Fagus sylvatica), European silver fir (Abies alba) and Norway spruce (Picea abies). The general climate of the Dinaric Mountains in Slovenia is a mix of influences from the Alps, the Mediterranean Sea and the Pannonia basin with an average annual temperature of $7^{\circ} \mathrm{C}$, ranging from an average monthly maximum of $18^{\circ} \mathrm{C}$ to an average monthly minimum of $-2^{\circ} \mathrm{C}$, and an average annual precipitation of $1700 \mathrm{~mm}$. 


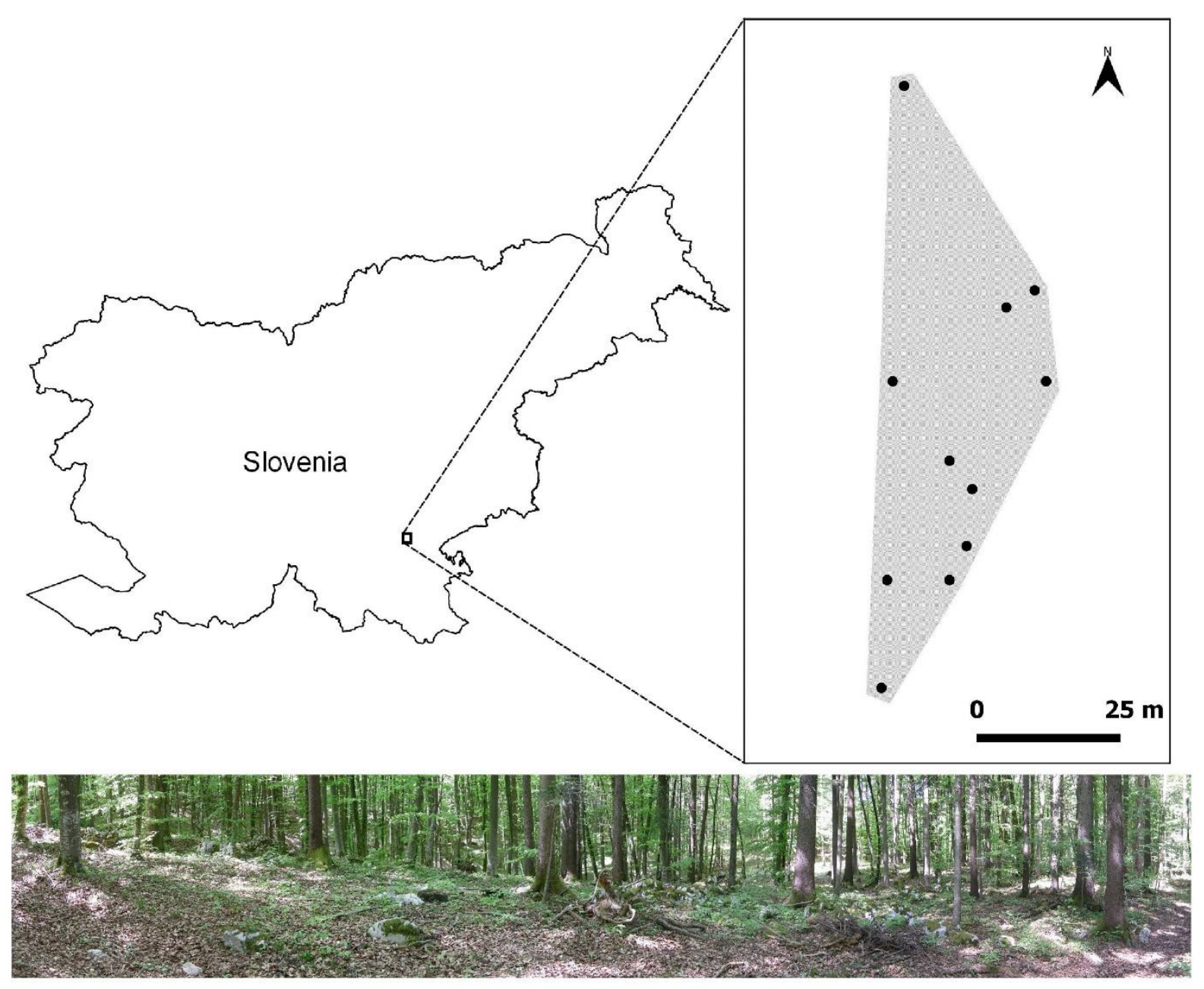

Figure 1. Cartographic view (at the top) and panoramic photo (bottom) of the experimental area, which covered about $2000 \mathrm{~m}^{2}$ (grey polygon). Black dots on the map represent locations of simulated urine marks (locations which were placed very close to each other are grouped and represented by a single dot).

The experimental area covered approximately $2000 \mathrm{~m}^{2}$ (fig. 1), therefore environmental conditions were considered consistent throughout. Weather conditions during the experiment (2 May to 22 May 2018) were typical for the region with occasional rain of variable intensity and duration (rain was observed on 11 days, and small hail was observed once), variable humidity and cloudiness, and variable wind conditions. According to the data from the closest manned weather station ( $7.3 \mathrm{~km}$ northeast of the study site), there was $75 \%$ average relative humidity in May 2018, average cloudiness was 55, average wind speed $1.4 \mathrm{~m} / \mathrm{s}$, average precipitation $69.4 \mathrm{~mm}$, and average air pressure $990 \mathrm{hPa}$. The closest automated weather station (5.5 km southwest of the study site) only collects precipitation data and recorded an average precipitation of $122 \mathrm{~mm}$ in May 2018 and $100.9 \mathrm{~mm}$ in the period when the experiment was performed (ARSO, 2019). However, weather conditions varied across the region at the time of the experiment and these data may thus not be fully representative for location of the experiment, where we measured only temperature. Average temperature at the location of the experiment during the experimental period was $16^{\circ} \mathrm{C}\left(\mathrm{min} .8^{\circ} \mathrm{C}\right.$, 
max. $24^{\circ} \mathrm{C}$ ). The average temperature during the morning sessions was $12^{\circ} \mathrm{C}\left(\min .8^{\circ} \mathrm{C}\right.$, max. $\left.15^{\circ} \mathrm{C}\right)$, and average temperature during the afternoon sessions was $20^{\circ} \mathrm{C}\left(\min .15^{\circ} \mathrm{C}, \max .24^{\circ} \mathrm{C}\right)$.

\section{Urine collection and handling}

We used domestic cat (Felis catus) urine from 24 unsterilized individuals. Urine was collected by veterinarians prior to sterilization using free catch, which is a common method for emptying the bladder before a surgery and is also recommended for experimental urine collection from felines (Kurien et al., 2004).

Urine was placed in a refrigerator (in an airtight plastic urine sample container) by the veterinarian as soon as it was collected and later frozen in order to preserve its original characteristics as much as possible. However, some of the urine volatiles may have escaped through the plastic containers. We froze most urine ( $72 \%$ of the total amount collected) the same day it was collected, $20 \%$ within one day, $6 \%$ within two and $3 \%$ within four days after collection. All urine was frozen in a single bigger plastic airtight container (i.e. we poured each round of collected urine into the same container stored in a freezer).

We collected urine in the period between 29 March 2018 and 26 April 2018. In total we collected $467 \mathrm{ml}$ of urine, of which $140 \mathrm{ml}$ was used in the experiment. The cats' age was available for 12 of them and ranged from 0.5 to three years (median = one year). Urine was collected from 13 females and 10 males (in one case, gender was not noted). Two females were confirmed to be pregnant at the time of urine collection, while we do not have pregnancy data for the rest. We melted frozen urine mixture and mixed it well immediately before it was sprayed on chosen microsites. Thus, we used the same mixture of urine on all simulated urine marking sites to ensure comparability between the chosen microsites.

\section{Experimental design and field methods}

We conducted the experiment in May 2018, when weather conditions at the location of the experiment are most representative, i.e. with temperatures and precipitation close to the annual average, and in the early phase of the vegetative season. The experiment started on 2 May in the morning, when we sprayed urine on all microsites that we had chosen in advance, and ended on 22 May in the afternoon.

We sprayed urine on two microsites on northerly and two on southerly oriented surfaces for each of the seven microsite types: overhanging bare rock (average angle of inclination $160^{\circ}$ ), vertical bare rock, sloping bare rock (average angle of inclination $47^{\circ}$ ), vertical rock overgrown with moss, 
deciduous tree trunk (beech), coniferous tree trunk (spruce), and juvenile spruce tree. This resulted in a total of 28 simulated urine marks, which enabled us to compare human-perceived smell intensity and longevity among microsites with different characteristics. Although there was some discrepancy regarding the use of differently oriented surfaces compared to previous studies on urine marking by felids (table 1), we chose to focus only on comparison between the northerly and southerly oriented surfaces, because the sun culminates in the south at the location of the experiment, so the most prominent (and thus most detectable) solar radiation difference should be between these two surfaces.

We marked chosen microsites with a small amount of lasting wood colour $7 \mathrm{~cm}$ (i.e. the width of the experimenter's palm) above the location where we sprayed urine (see supplementary fig. S1). Spraying urine below the colour mark ensured that urine preserved its original characteristics (scent may change if applied over aromatic wood colour marking). We marked all experimental sites with colour around a month before the start of the experiment to ensure the absence of scent from the colour, which could interfere with the detection of urine scent.

The height of simulated urine marks varied, because it was adjusted according to the characteristics of each experimental microsite in order to ensure the most representative place on available objects. The average height of simulated urine marks was $\sim 50 \mathrm{~cm}$ (ranging from $20 \mathrm{~cm}$ to 80 $\mathrm{cm}$ ), which roughly corresponds to the heights of urine scent marks made by Eurasian lynx and European wildcat (Ruiz-Olmo et al., 2013; unpublished personal observations).

In the available literature there is a lack of information on the amount of urine that is excreted by various wild felids when they are scent-marking. Based on personal communication with other researchers and veterinarians (A. Zaninović, K. Vogt, and J. Teunissen van Mannen), as well as based on our own observations during snow tracking of felids in the Dinaric Mountains, we estimate that wild Eurasian lynx usually spray $\sim 5-20 \mathrm{ml}$ during urine marking, which is also in the range of domestic cats and European wildcats. Based on this information, we sprayed $5 \mathrm{ml}$ of urine per microsite, using a disposable plastic $20 \mathrm{ml}$ syringe (PIC Solution Syringe, Artsana S.p.A, Grandate (CO) - Italy), perpendicular to the surface from a distance of $\sim 7 \mathrm{~cm}$. During the pilot tests we found this combination to be optimal in terms of an adequate simulation of actual felid spraying and to ensure highest comparability between the sprayed microsites. We ensured comparability also by: choosing a homogeneous and smallest possible (fig. 1) experimental study area with all required objects, choosing microsites with similar characteristics, spraying urine consistently at all chosen spraying sites (i.e., same intensity of spraying), and conducting experiment at all microsites simultaneously.

\section{Data collection}


The presence and intensity of urine odour was detected and estimated by the experimenter inhaling through the nose (sniffing). Data were always collected by the same person (M.M.) to ensure comparability among the microsites and throughout the experiment. Although humans perceive odour differently from non-human mammals (Walker \& Jennings, 1991), we assume that human and felid detection of scent is comparable on a relative scale. Since we focused on differences in scent persistence on microsites with different characteristics, it was important to ensure consistent detection of urine scent by: (1) ensuring that always the same person was sampling all sites; (2) taking short rests for recalibration of the olfactory system, with rest times generally increasing with decreasing urine scent (see supplementary table S1 for details on the duration of intervals between individual sniffs); (3) always beginning with sniffing from afar and gradually approaching the source of the urine odour; and (4) once the urine smell started to fade out more intensively, starting each sampling session with investigation of those microsites where urine scent was the weakest in the previous sampling session, and finishing with investigation of the microsites with the strongest smell in the previous sampling session (sampling session represented 28 sniffs, one per microsite). We ranked the intensity of smell as perceived by the experimenter into predefined intensity classes (using $5 \mathrm{~cm}$ and $15 \mathrm{~cm}$ long sticks). We defined the classes as follows (number represents intensity of detected urine smell from lowest to highest): 0 - urine smell cannot be confirmed; 1 - urine is smelled slightly, but is certainly detectable; 2 - urine smell well detectable but only at close range (i.e. up to $5 \mathrm{~cm}$ ); 3 - urine smell detected at a distance of $5-15 \mathrm{~cm} ; 4-$ urine smell detected at a distance of $15 \mathrm{~cm}$ or more.

We sniffed each urine-sprayed site until there was no urine smell detectable (i.e., intensity class " 0 - no urine smell") in at least three consecutive sampling sessions in order to detect the actual fade-out time, because even if the smell cannot be detected at a given moment, it may possibly be detected again the next day (i.e., in the following sampling sessions) due to changes in microclimate conditions, which influence evaporation and smell detection (Conover, 2007).

We investigated (i.e. sniffed) all 28 simulated urine marks two times per day (early morning and afternoon/evening sampling session; see supplementary table S1), since there are indications that the morning hours around sunrise and evening hours around sunset are the best times for scent detection, and the middle of a bright sunny day the worst (Conover, 2007).

\section{Data analysis}

We excluded small conifers from the analysis, because it was difficult to reliably distinguish between cat urine smell and juvenile conifer smells when cat urine was becoming faint, thus data would not be comparable across microsites. Therefore we used 24 microsites for the analysis. 
We converted absolute sniffing times (i.e., date and time at the moment when the intensity of smell was defined) to relative times (i.e., time interval between the moment of urine deposition at given microsite and the moment of scent intensity determination).

We used area under the curve (AUC; Tai, 1994) to estimate scent persistence and we calculated AUC for each of the 24 microsites from the data of classified urine scent intensity ( $y$ axis) and relative time ( $x$ axis). In all cases, we defined maximum scent intensity (i.e., intensity 4 ) as the default value for the moment of urine deposition (i.e. zero relative time). We used AUC values as input values for data visualization and statistical analyses.

We conducted all statistical analyses and data visualization in R-3.6.0 (R Core Team, 2019), using the multcomp (Hothorn et al., 2008) and ggplot2 (Wickham, 2016) packages. We used a backward elimination model selection procedure to determine the most appropriate ANOVA model for our data. Variability of data was high, thus we performed ANOVA tests on log-transformed data (i.e., we log-transformed the response variable). The full model contained scent persistence (i.e., $\mathrm{AUC}$ ) as a response variable and microsite type, orientation and their interaction as explanatory variables. Then, we performed multiple comparisons on the most appropriate model using the general linear hypothesis function, to compare AUC values at different microsites. We focused on nine comparisons. Namely, we compared urine scent persistence on different types of vertical surfaces (vertical rock with moss, vertical bare rocks, coniferous and deciduous tree trunks) and on bare rocks of different tilts (overhanging, vertical and sloping bare rocks).

\section{Results}

We detected felid urine scent for a maximum of $465 \mathrm{~h}$ (approximately 19 days; fig. 3). It was on average detectable the longest on the vertical rocks overgrown by moss (mean $421 \mathrm{~h}$, range 393-465 h; fig. 3), followed by the coniferous tree trunks (mean 368 h, range 293-440 h; fig. 3). Urine scent on the deciduous tree trunks and on the vertical and sloping bare rocks disappeared fastest (average 58 $\mathrm{h}$, range 33-81 h; fig. 3). Among the bare rocks with different tilts, urine scent persisted longest on overhanging surfaces (average $247 \mathrm{~h}$, range $239-249 \mathrm{~h}$; fig. 3). Thus, in general urine scent was most persistent on rough surfaces, surfaces covered with moss, and surfaces with overhanging tilts (figs 2 and 3). 
Interaction between the surface type and orientation was not detected as significant $\left(F_{5,12}=\right.$ $1.52, P=0.25)$, nor was the effect of orientation of the marked surface $\left(F_{1,17}=2.01, P=0.18\right)$. Therefore we eliminated these two explanatory variables from the model and continued with a model that only contained surface type as explanatory variable, which had a strong effect on scent persistence $\left(F_{5,18}=109.9, P<0.001\right)$. Although we did not detect significant effects of orientation of the marked surface on scent persistence, persistence was somewhat greater on the northerly compared to the southerly oriented surfaces (mean AUC 475 and 429, respectively).

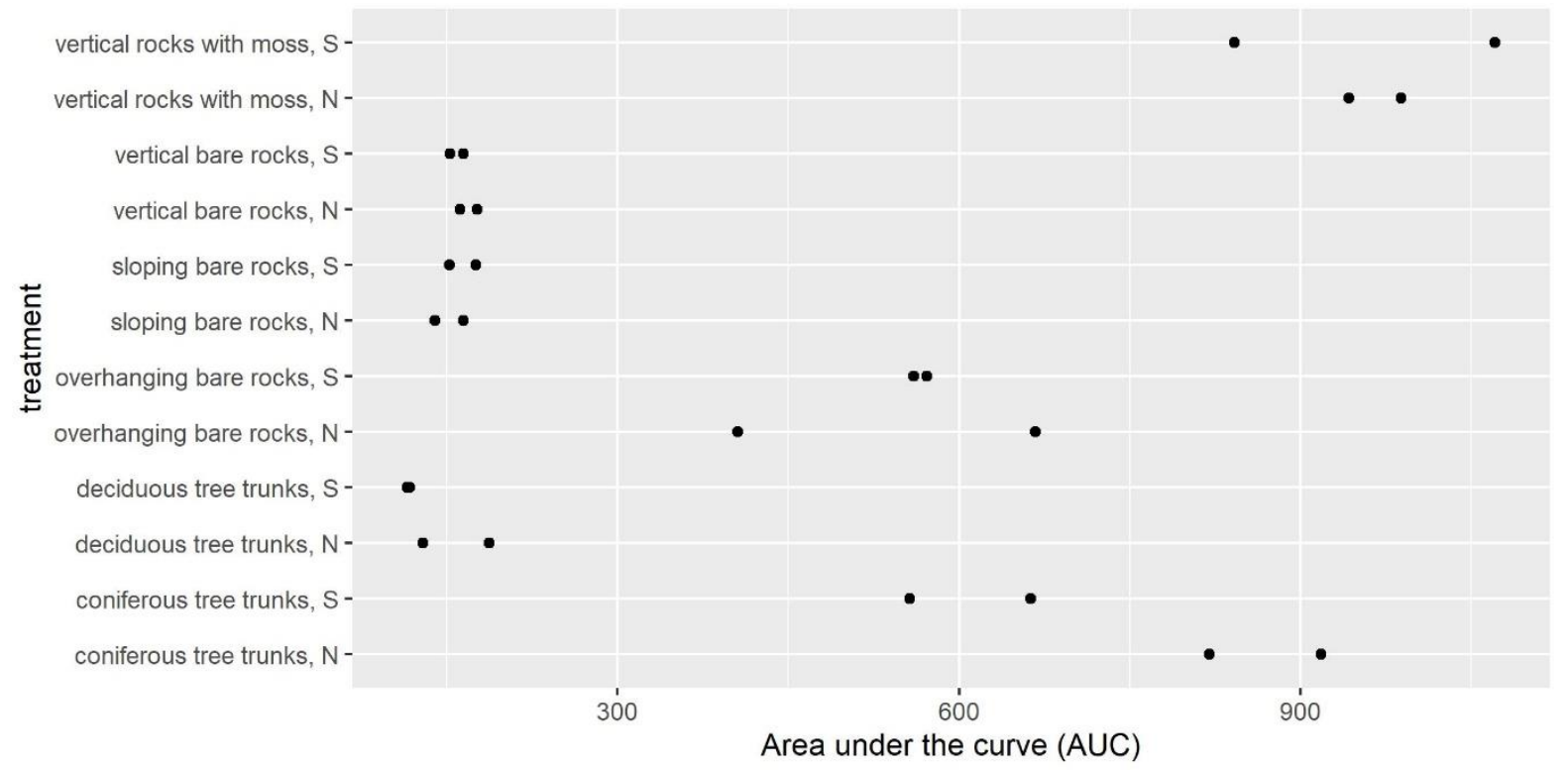

Figure 2. Persistence of urine scent (measured by AUC) with respect to the orientation, surface type and tilt of the marked microsite. Abbreviations: $\mathrm{N}$, north; $\mathrm{S}$, south. 


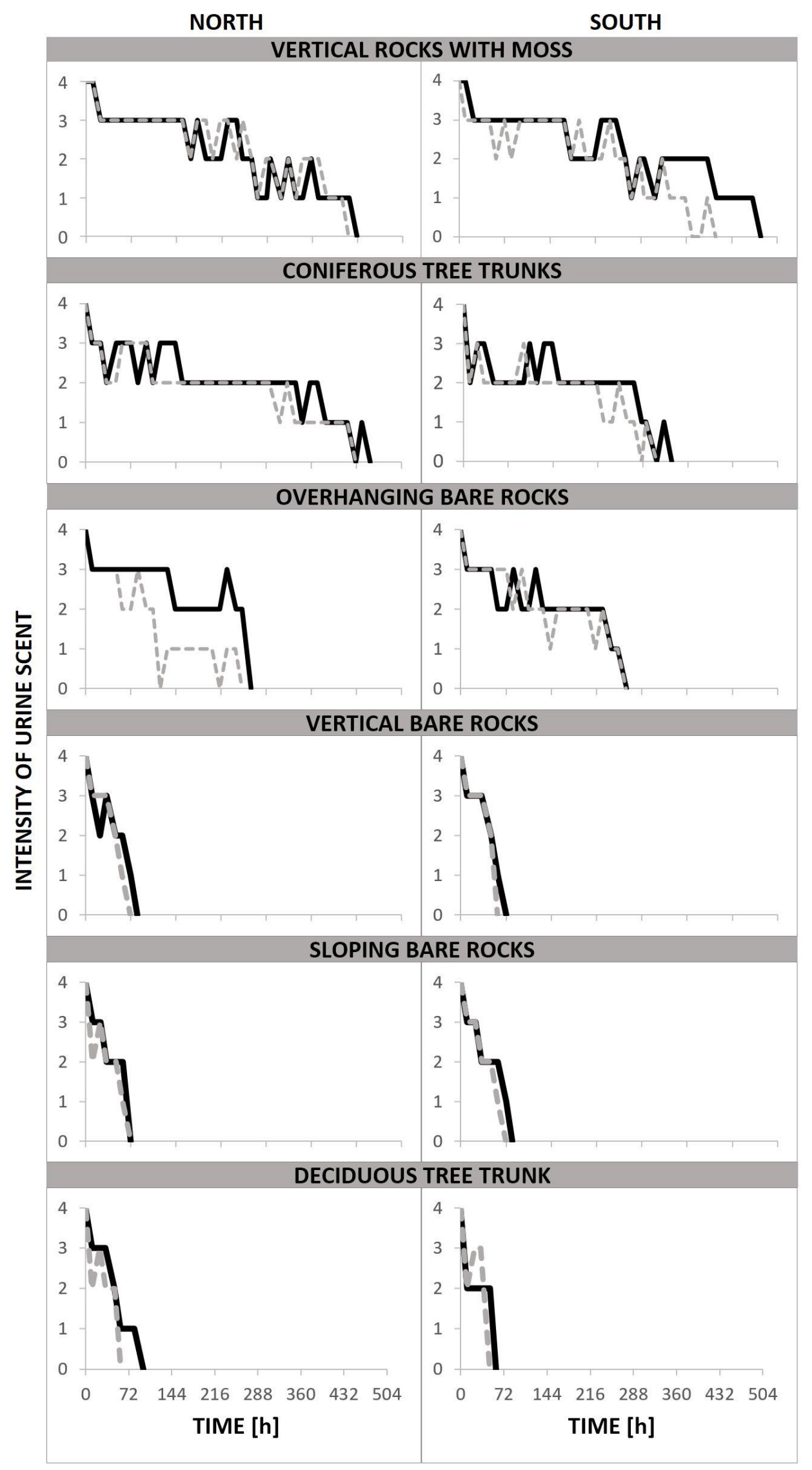

Figure 3. Recorded persistence of urine smell on analysed (24) microsites. Both black solid line and dashed grey line represent detected changes in urine odour intensity over time. 


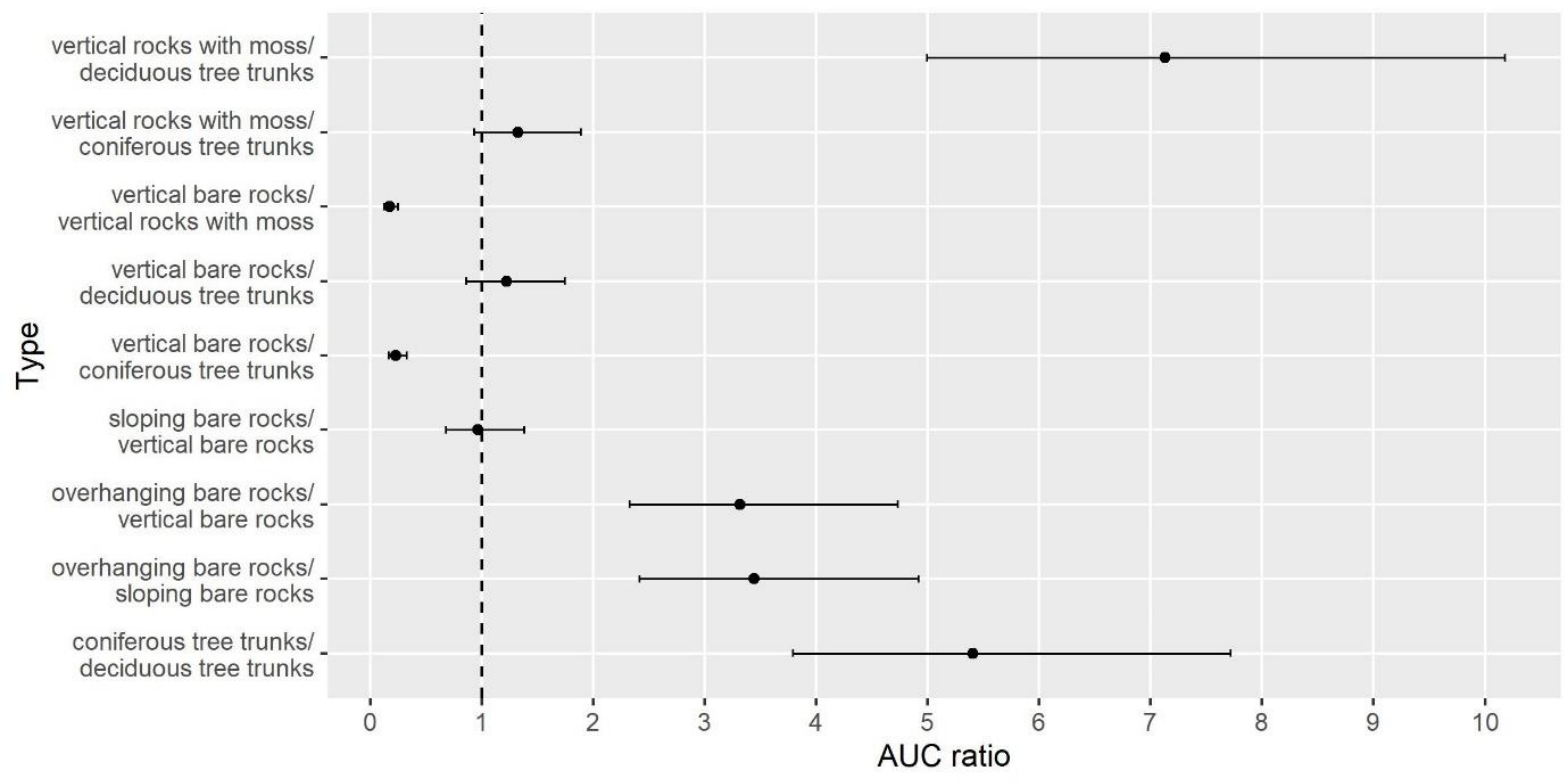

Figure 4. Estimated ratios in scent persistence on different surface types, with associated $95 \%$ confidence intervals. Because inversed log transformation was used, dots represent the ratio between AUC means on two different surface types and confidence intervals are asymmetric (e.g., urine scent on overhanging bare rocks is about 3.4 times the scent on sloping bare rocks, with confidence interval 2.4-4.9). Differences in smell persistence are not significant for pairs whose confidence intervals include the value 1 (marked with the broken line).

Urine scent persisted significantly better on the rocks with moss than on bare rocks; on the rocks with moss than on deciduous tree trunks; on the coniferous than on deciduous tree trunks; and on coniferous tree trunks than on bare rocks (fig. 4). Among vertical object types, we found the largest difference between the vertical rocks with moss and deciduous tree trunks (fig. 4). Among differently tilted bare rocks, scent persisted significantly better on the overhanging rocks than on the vertical and sloping bare rocks (fig. 4).

\section{Discussion}

We experimentally tested the effect of environmental variables (substrate type, tilt and orientation of marked surfaces) on scent mark persistence as perceived by humans to evaluate the importance of marking site characteristics in felid olfactory communication. Our study indicates that substrate type and surface tilt can be essential variables in scent mark persistence, while orientation of marking sites appears less important, at least in lowland temperate regions. The results of this study provide a better understanding of data from previous research and give us insight into the adaptive significance of use and selection of specific microsites for urine marking by felids. 
Prolonged persistence was suggested to be an important feature of felid scent marks, as it can decrease the need to frequently refresh the scent marks and thus lower the energetic costs associated with the marking of large territories (Allen et al., 2017). The maximum persistence of 19 days that we observed for felid urine corresponds well to the documented return rates to scent marks (14-25 days) for pumas (Puma concolor) (Allen et al., 2016b). This indicates that return rate of felids to refresh scent marks is likely based on scent persistence. Our results are generally also in line with the observed preferences in use and selection of microsites for scent-marking by wild felid species (table 1), thus further supporting evidence that in their marking behaviour felids strive to prolong the persistence of scent marks.

Based on human perception of smell, we observed that surface type importantly affects persistence of urine marks, with the scent most persistent on surfaces with a rough texture, i.e. on rocks overgrown by moss and coniferous tree trunks. These findings support the assumption that moss can prolong the durability of a scent message, likely because it increases the surface area of the object and captures more urine (Allen et al., 2017). Our results are also in accordance with the suggestion that plants better retain scent, presumably due to the slower release of volatile organic compounds (Barja, 2003; Conover, 2007; Ruiz-Olmo et al., 2013). Furthermore, rough surfaces may capture urine better than smooth ones because of more crevices and binding sites (Conover, 2007). Thus, it appears that marking preferences for rough surfaces observed in felids, such as Eurasian lynx (Vogt et al., 2016b; Allen et al., 2017), have an adaptive value, since such behaviour improves the persistence of olfactory signalling.

Our results can be relevant also for other species, where similar marking behaviour has been noted. For example, giant pandas (Ailuropoda melanoleuca) are more likely to urine-mark trees with the roughest bark, while smooth barked trees were avoided. However, pandas did not select trees covered with moss, but marked them with regard to availability. Authors suggest that the reason for this might be in moss preventing the urine from contacting the bark's sap, which has been proposed to bind scent chemicals and increase signal persistence (Nie et al., 2012). This assumption could be tested with experiments similar to ours, in which the persistence of urine marks would be compared between coniferous tree trunks with and without moss.

As expected, urine scent was significantly more persistent (on average more than threefold) on overhanging compared to vertical or sloping bare rocks (fig. 4). This supports the hypothesis that surfaces with overhanging tilts better shelter scent from precipitation and solar radiation and thus preserve scent better (Ahlborn \& Jackson, 1988; Sharma et al., 2006; Allen et al., 2017), and is consistent with previous studies on selection of marking sites by wild felids (e.g. snow leopards, Panthera uncia: Ahlborn \& Jackson, 1988; Jackson, 1996; Sharma et al., 2006; and tigers, P. tigris: Smith et al., 1989). On the other hand, Allen et al. (2017) found that Eurasian lynx most often 
sprayed urine on vertically tilted rocks and that sloping rocks were avoided according to availability. However, we observed relatively equal persistence of scent on surfaces with vertical and sloping tilts. This discrepancy might be affected by the accessibility of the potential marking sites, which could influence their use and selection (Sharma et al., 2006; Allen et al., 2017), or by the level of precipitation and exposure to other environmental factors in the region and season. Our experiment was limited to a single study site and one season; therefore we recommend further comparative research in different regions and different seasons to establish the influence of the environmental factors. This would add to the understanding of scent-marking behaviour in felids across various ecological conditions and its adaptive significance.

Despite reports of snow leopards preferring northerly oriented surfaces for scent-marking (Ahlborn \& Jackson, 1988; Jackson, 1996; Sharma et al., 2006; but see different results reported for Eurasian lynx by Allen et al., 2017), we did not detect significant differences between northerly and southerly oriented surfaces, which could be an effect of low sample size. However, we observed a tendency in favour of northerly-oriented surfaces, especially on coniferous tree trunks (fig. 2). Further tests on the importance of this parameter are advised.

We observed the discoloration of moss (see supplementary fig. S2) five days after urine deposition, which could be a consequence of fatty acids in the urine (Ahlborn \& Jackson, 1988; RuizOlmo et al., 2013). Such visual cues could potentially influence marking behaviour by attracting additional attention of the receiver to the marking site.

We could detect felid urine scent for up to 19 days, which is consistent with reports from Switzerland and Nepal, where scent-markings of Eurasian lynx and tigers could be perceived for up to three weeks by a human (Smith et al., 1989; Vogt et al., 2014). Relatively long persistence of smell of felid urine may be a consequence of its chemical composition, such as lactones, lipids, and other volatile compounds that are believed to allow marks to persist (Asa, 1993; Burger et al., 2008). It should be noted, however, that humans have in general poorer sense of smell than other mammals (Walker \& Jennings, 1991, but see McGann, 2017). Therefore, detection of felid urine scent is likely longer for felids compared to humans, but so far exact information on this is lacking. To obtain absolute times of felid scent persistence, we suggest laboratory tests at a chemical level or use of trained captive animals. We also suggest testing how the amount of urine affects scent persistence, because this could influence the marking behaviour (i.e. it may make more sense for felids to rather use smaller amount of urine on a higher number of marking sites).

Another limitation of our study was that we did not control various weather factors, such as temperature, humidity, wind and precipitation. This was connected with our decision to conduct the experiment in natural conditions in the habitat of wild felids, which enabled us to obtain realistic results on the effects of tested parameters. In order to understand effects of other factors 
mentioned above, we recommend tests under controlled conditions (i.e. in a laboratory). Similar approach could be used to better understand the effects of the volatile organic compounds of various plant species on the degradation of felid scent marks, which could importantly influence scent persistence (Owen et al., 2001; Ruiz-Olmo et al., 2013).

In conclusion, we present findings on the effects of several environmental factors on the persistence of scent marks in felids, based on experimental framework. We confirmed that several characteristics of the marking site affect urine scent persistence. Urine scent was most persistent on rough surfaces, surfaces covered with moss and surfaces with overhanging tilts. We believe this knowledge will assist researchers in the interpretation of their data on felid scent-marking to evaluate the adaptive significance of this behaviour. Results could be valuable also for other animal groups, since diverse vertebrates appear to establish similar scent-marking strategies to increase the efficiency of marking behaviour and minimize energetic costs to signallers (Alberts, 1992). Furthermore, our study improves the understanding of communication strategies in animals, and highlights the underlying mechanisms influencing efficiency of marking behaviour. Thus, it can be relevant for conservation and management (including monitoring) of species that rely on scents in their communication. Finally, the experimental framework developed within this study could be a useful approach for future studies on animal marking behaviour.

\section{Acknowledgements}

We are grateful to Ana Zaninović, Nuša Schumet, Jana Mede and Magda Piotrowska for urine collection, storage and information on the characteristics of domestic cat urine and urinating behaviour. We also benefited from discussions with Kristina Vogt and Jennapher Teunissen van Manen. Furthermore, we thank Katarina Košmelj, Jared Laufenberg, Jernej Javornik and Dejan Bordjan, for their valuable advice on statistical analyses. We are also grateful to two anonymous reviewers for their constructive comments on the manuscript. All the work conducted by the first author was self-funded, while the senior author was partly supported by the Slovenian Research Agency (grant P4-0059).

\section{Authors contributions}

M.M. designed and partly financed the study, carried out the field work and data analysis, and wrote the first draft. M.K. conceptualized the research, provided assistance at all stages, wrote additional parts of the manuscript and improved the text. Both authors interpreted the data and reviewed the text. 


\section{References}

Ahlborn, G.G. \& Jackson, R.M. (1988) Marking in free-ranging snow leopards in west Nepal: a preliminary assessment. In: H. Freeman (Ed) Proceedings of the 5th International Snow Leopard Symposium, pp. 25-49. Seattle, Washington: International Snow Leopard Trust and Wildlife Institute of India.

Alberts, A.C. (1992) Constraints on the design of chemical communication systems in terrestrial vertebrates. Am. Nat., 139, S62-S89. doi: 10.1086/285305.

Allen, M.L., Wittmer, H.., Houghtaling, P., Smith, J., Elbroch, L.M. \& Wilmers, C.C. (2015) The role of scent marking in mate selection by female pumas (Puma concolor). PLoS One, 10, e0139087. doi: 10.1371/journal.pone.0139087.

Allen, M.L., Wittmer, H.U., Setiawan, E., Jaffe, S. \& Marshall, A.J. (2016a) Scent marking in Sunda clouded leopards (Neofelis diardi): novel observations close a key gap in understanding felid communication behaviours. Sci. Rep., 6, 35433. doi: 10.1038/srep35433.

Allen, M.L., Yovovich, V. \& Wilmers, C.C. (2016b) Evaluating the responses of a territorial solitary carnivore to potential mates and competitors. Sci. Rep., 6, 27257. doi: 10.1038/srep27257.

Allen, M.L., Hočevar, L., de Groot, M. \& Krofel, M. (2017) Where to leave a message? The selection and adaptive significance of scent-marking sites for Eurasian lynx. Behav. Ecol. Sociobiol., 71, 136. doi: 10.1007/s00265-017-2366-5.

ARSO (2019) Archive of meteorological data. Agencija Republike Slovenije za okolje. http://www.meteo.si/met/sl/archive/ (last accessed 29 Nov. 2019).

Asa, C.S. (1993) Relative contributions of urine and anal-sac secretions in scent marks of large felids. Am. Zool.., 33, 167-172. doi: 10.1093/icb/33.2.167.

Bailey, T.N. (1974) Social organization in a bobcat population. J. Wildlife Manage., 38, 435-446. doi: $10.2307 / 3800874$.

Barja, I. (2003) Patrones de señalización con heces en el lobo ibérico. Etología, 11, 1-7.

Barja, I. (2009) Decision making in plant selection during the faecal-marking behaviour of wild wolves. Anim. Behav., 77, 489-493. doi: 10.1016/j.anbehav.2008.11.004.

Black-Décima, P. (2000) Home range, social structure, and scent marking behavior in brown brocket deer (Mazama gouazoubira) in a large enclosure. Mastozool. Neotrop., 7, 5-14.

Bothma, J. du P. \& le Richet, E.A.N. (1995) Evidence of the use of rubbing, scent-marking and scratching-posts by Kalahari leopards. J. Arid Environ., 29, 511-517. doi: 10.1016/S01401963(95)80023-9. 
Burger, B.V., Viviers, M.Z., Bekker, J.P.I., le Roux, M., Fish, N., Fourie, W.B. \& Weibchen, G. (2008) Chemical characterization of territorial marking fluid of male Bengal tiger, Panthera tigris. J. Chem. Ecol., 34, 659. doi: 10.1007/s10886-008-9462-y.

Caragiulo, A., Pickles, R.S.A., Smith, J.A., Smith, O., Goodrich, J. \& Amato, G. (2015) Tiger (Panthera tigris) scent DNA: a valuable conservation tool for individual identification and population monitoring. Conserv. Genet. Resour., 7, 681-683. doi: 10.1007/s12686-015-0476-9.

Clapham, M., Nevin, O.T., Ramsey, A.D. \& Rosell, F. (2012) A hypothetico-deductive approach to assessing the social function of chemical signalling in a non-territorial solitary carnivore. PLoS One, 7, e35404. doi: 10.1371/journal.pone.0035404.

Conover, R.C. (2007) Predator-Prey Dynamics: The Role of Olfaction. CRC Press/Taylor \& Francis Group, Boca Raton, FL, USA.

Eaton, R.L. (1970) Group interactions, spacing and territoriality in cheetahs. Z. Tierpsychol., 27, 481491. doi: 10.1111/j.1439-0310.1970.tb01882.x.

Feldman, H.N. (1994) Methods of scent marking in the domestic cat. Can. J. Zool., 72, 1093-1099. doi: 10.1139/z94-147.

Gese, E.M. \& Ruff, R.L. (1997) Scent-marking by coyotes, Canis latrans: the influence of social and ecological factors. Anim. Behav., 54, 1155-1166. doi: 10.1006/anbe.1997.0561.

Gorman, M.L. \& Trowbridge, B.J. (1989) The role of odor in the social lives of carnivores. In: J.L. Gittleman (Ed) Carnivore Behavior, Ecology, and Evolution, pp. 57-88. Springer US, Boston, MA, USA. doi: 10.1007/978-1-4757-4716-4_3.

Gosling, L.M. \& Roberts, S.C. (2001) Scent-marking by male mammals: Cheat-proof signals to competitors and mates. In: Slater P.J.B., Rosenblatt J.S., Snowdon C.T., Roper T.J. (Eds) Advances in the Study of Behavior, Vol. 30, pp. 169-217. Academic Press, London. doi: 10.1016/S0065-3454(01)80007-3.

Haswell, P.M., Jones, K.A., Kusak, J. \& Hayward, M.W. (2018) Fear, foraging and olfaction: how mesopredators avoid costly interactions with apex predators. Oecologia, 187, 573-583. doi: 10.1007/s00442-018-4133-3.

Hirano, Z.M.B., Correa, I.C. \& de Oliveira, D.A.G. (2008) Contexts of rubbing behavior in Alouatta guariba clamitans: a scent-marking role? Am. J. Primatol., 70, 575-583. doi: 10.1002/ajp.20531.

Hothorn, T., Bretz, F. \& Westfall, P. (2008) Simultaneous inference in general parametric models. Biom. J., 50, 346-363. doi: 10.1002/bimj.200810425.

Jackson, R.M. (1996) Home Range, Movements and Habitat Use of Snow Leopard (Uncia Uncia) in Nepal. PhD dissertation. University of London (External Programme), London, UK. 
Kimura, R. (2000) Relationship of the type of social organization to scent-marking and mutualgrooming behaviour in Grevy's (Equus grevyi) and Grant's Zebras (Equus burchelli bohmi). J. Equine Sci., 11, 91-98.

Kitchener, A.C. (2000) Are cats really solitary? Lutra, 43, 1-10.

Krofel, M., Hočevar, L. \& Allen, M.L. (2017) Does human infrastructure shape scent marking in a solitary felid? Mamm. Biol., 87, 36-39. doi: 10.1016/j.mambio.2017.05.003.

Kurien, B.T., Everds, N.E. \& Scofield, R.H. (2004) Experimental animal urine collection: a review. Lab. Anim., 38, 333-361. doi:10.1258/0023677041958945.

Mattisson, J., Segerström, P., Persson, J., Aronsson, M., Rauset, G.R., Samelius, G. \& Andrén, H. (2013) Lethal male-male interactions in Eurasian lynx. Mamm. Biol., 78, 304-308. doi: 10.1016/j.mambio.2012.11.006.

McGann, J.P. (2017) Poor human olfaction is a 19th-century myth. Science, 356, eaam7263. doi: 10.1126/science.aam7263.

Mellen, J.D. (1993) A comparative analysis of scent-marking, social and reproductive behavior in 20 species of small cats (Felis). Am. Zool., 33, 151-166. doi: 10.1093/icb/33.2.151.

Mertl-millhollen, A.S. (2006) Scent marking as resource defense by female Lemur catta. Am. J. Primatol., 68, 605-621. doi: 10.1002/ajp.20255.

Nie, Y., Swaisgood, R.R., Zhang, Z., Hu, Y., Ma, Y. \& Wei, F. (2012) Giant panda scent-marking strategies in the wild: role of season, sex and marking surface. Anim. Behav., 84, 39-44. doi: 10.1016/j.anbehav.2012.03.026.

Owen, S.M., Boissard, C. \& Hewitt, C.N. (2001) Volatile organic compounds (VOCs) emitted from 40 Mediterranean plant species: VOC speciation and extrapolation to habitat scale. Atmos. Environ., 35, 5393-5409. doi: 10.1016/\$1352-2310(01)00302-8.

Piñeiro, A. \& Barja, I. (2012) The plant physical features selected by wildcats as signal posts: an economic approach to fecal marking. Naturwissenschaften, 99, 801-809. doi: 10.1007/s00114-012-0962-9.

R Core Team (2019) R: A language and environment for statistical computing. R Foundation for Statistical Computing, Vienna, Austria. https://cran.r-project.org.

Remonti, L., Balestrieri, A., Smiroldo, G. \& Prigioni, C. (2011) Scent marking of key food sources in the Eurasian otter. Ann. Zool. Fennici, 48, 287-294. doi: 10.5735/086.048.0503.

Rosenthal, G.G. \& Ryan, M.J. (2000) Visual and acoustic communication in non-human animals: a comparison. J. Biosci., 25, 285-290. doi: 10.1007/BF02703937.

Rostain, R.R., Ben-David, M., Groves, P. \& Randall, J.A. (2004) Why do river otters scent-mark? An experimental test of several hypotheses. Anim. Behav., 68, 703-711. doi: 10.1016/j.anbehav.2003.10.027. 
Ruiz-Olmo, J., Such-Sanz, A. \& Piñol, C. (2013) Substrate selection for urine spraying in captive wildcats. J. Zool., 290, 143-150. doi: 10.1111/jzo.12025.

Roper, T.J., Conradt, L., Butler, J., Christian, S.E., Ostler, J. \& Schmid, T.K. (1993) Territorial marking with faeces in badgers (Meles meles): a comparison of boundary and hinterland latrine use. Behaviour, 127, 289-307. doi: 10.1163/156853993X00074.

Sharma, S., Dutta, T. \& Bhatnagar, Y.V. (2006) Marking site selection by free ranging snow leopard (Uncia uncia). In: J.A. McNeely, T.M. McCarthy, A. Smith, L. Olsvig-Whittaker, \& E.D. Wikramanayake (Eds) Conservation Biology in Asia, pp. 197-213. Society for Conservation Biology Asia Section and Resources Himalaya, Kathmandu, Nepal.

Smith, J.L.D., McDougal, C. \& Miquelle, D. (1989) Scent marking in free-ranging tigers, Panthera tigris. Anim. Behav., 37, 1-10. doi: 10.1016/0003-3472(89)90001-8.

Soler, L., Lucherini, M., Manfredi, C., Ciuccio, M. \& Casanave, E.B. (2009) Characteristics of defecation sites in the Geoffroy's cat Leopardus geoffroyi. Mastozool. Neotrop., 16, 485-489.

Sunquist, M. \& Sunquist, F. (2002) Wild Cats of the World. First Edition. The University of Chicago Press, Chicago, IL, USA.

Tai, M.M. (1994) A mathematical model for the determination of total area under glucose tolerance and other metabolic curves. Diabetes Care, 17, 152-154. doi: 10.2337/diacare.17.2.152.

Vogt, K., Zimmermann, F., Kölliker, M. \& Breitenmoser, U. (2014) Scent-marking behaviour and social dynamics in a wild population of Eurasian lynx Lynx lynx. Behav. Process., 106, 98-106. doi: 10.1016/j.beproc.2014.04.017.

Vogt, K., Boos, S., Breitenmoser, U. \& Kölliker, M. (2016a) Chemical composition of Eurasian lynx urine conveys information on reproductive state, individual identity, and urine age. Chemoecology, 26, 205-217. doi: 10.1007/s00049-016-0220-2.

Vogt, K., Hofer, E., Ryser, A., Kölliker, M. \& Breitenmoser, U. (2016b) Is there a trade-off between scent marking and hunting behaviour in a stalking predator, the Eurasian lynx, Lynx lynx? Anim. Behav., 117, 59-68. doi: 10.1016/j.anbehav.2016.04.004.

Walker, J.C. \& Jennings, R.A. (1991) Comparison of odor perception in humans and animals. In: D.G. Laing, R.L. Doty \& W. Breipohl (Eds) The Human Sense of Smell, pp. 261-280. Springer, Berlin/Heidelberg, Germany. doi: 10.1007/978-3-642-76223-9_13.

Wickham, H. (2016) ggplot2: elegant graphics for data analysis. Springer-Verlag, New York, NY, USA.

Zala, S.M., Potts, W.K. \& Penn, D.J. (2004) Scent-marking displays provide honest signals of health and infection. Behav. Ecol., 15, 338-344. doi: 10.1093/beheco/arh022. 